\title{
Beiträge zur feinern normalen Anatomie des menschlichen Geruchsorganes.
}

Von

\author{
Dr. Hermann Snchannek, \\ Privatdocent für Rhinologie und Laryngologie zn Zürich.
}

Hierzu Tafel XIV.

Unzweifelhaft gebührt Todd und Bowmann (67) das Verclienst, in der 1847 erschienenen zweiten Abtheilung ihrer physiological anatomy and physiology of man auf die intensiv braungelbe Färbung und suceulente Beschaffenheit der Geruchsgegend bei Säugethieren aufmerksam gemacht zu haben. Auch die Ursache dieser auffallenden Färbung wurde bereits von ihnen richtig erkannt und als Pigmentablagerung in den Zellen des nicht wimpernden Oberflächen- und des Drüsenepithels beschrieben.

Nach Eckhardt (15) (1855), der vorwiegend, vielleicht nur am Frosch untersucht zu haben scheint, denn er spricht von langen feinen Härchen auf dem Geruchsepithel, sind zwei Zellformen zu unterscheiden, von denen entweder die Epithelzellen oder die zwischen ihnen gelegenen stumpf endigenden Fasern die wahren Enden des Geruchsnerven darstellen.

Ecker (14) versuchte fast gleichzeitig (1855) und unabhängig von Eckhardt anch beim Menschen und Säugethier Isolationspräparate unter Zuhülfenahme des liq. conservativus (Kochsalz-Alaun-Sublimatgemisch) und Kali bichromic.-Lösungen herzustellen, konnte aber nur eine Art Epithelzellen nachweisen und hält die schlanken Gebilde zwischen den Epithelzellen für Ersatzzellen. Einen oberflächlichen Wimperbesatz vermisste er.

In den Verhandlungen der phys. med. Ges. zu Würzburg Bd. V, S. 17 heisst es in dem Bericht über die Section eines Enthaupteten (1855), dass nach der iibereinstimmenden Behauptung voll Gegenbaur, Leydig und Müller, ausser den übrigen Par- 
thieen der Nasenschleimhaut auch die regio olf., die nach ToddBowmann und Kölliker flimmerlos wäre, einen Wimperbesatz zeigte. Die Epithelzellen besassen hier und da zwei, selbst drei hintereinander liegende Kerne. Die Bowmann'schen (von Kölliker so benannten) Drïisen ähnelten weniger den tubnlösen Gebilden beim Thier als gewöhnlichen acinösen Schleimdrüsen (Leydig!). $18 \tilde{7} 7$ indessen erschien Leydig. (39) bei der Ziege die mit schlanchförmigen Driisen versehene Geruchsschleimhaut cilienlos. Ueber das Eintreten von Nerven ins Riechepithel traut sich derselbe Autor keine bestimmte Meinung zn, jedenfalls nsetzten sie sich nicht in die Epithelzellen fort, sondern in eigene, das Licht stark brechende Streifen, die sich zwischen den Zellen befänden." Offenbar hatte Leydig von der inzwischen erschienenen Schrift M. Sc hultze's (58) (1856) keine gründlichere Kemntniss genommen. In ihr tritt nämlich M. Schultze auch für die Existenz zweier morphologisch und functionell ganz verschiedener Zellarten ein und bezeichnet die ron Ecker als Ersatzzellen gedeuteten Gebilde als Riechyellen. Er unterscheidet somit scharf einerseits zwischen den sogenannten Stützzellen, schlanken cylindrischen Epithelzellen mit breitem, prismatischem, peripherem Ende und schmäleren, schlanken, längeren, häufig gegabelten Fussenden und ovalem, im oberen Theil der Zelle sitzenden Kern, andererseits den spindelförmigen Riechzellen mit dickerem, homogenem, peripherem und feinem, varikösem, centralen Fortsatz. In letateren sieht er die eigentlichen Sinneszellen der varikösen centralen Fussenden dieser Zellen halber, die den feinsten Axencylinderfortsätzen täuschend ähnlich sahen. Einen Zusammenhang zwischen Olfactoriusendigungen und Riechzellen zu constatiren, gelang: ihm nicht ${ }^{1}$ ). Seine Theorie verfocht Schultze auch den gegentheiligen Behauptungen Reichert's (5̃5), (der in der reg. olf. des Kaninchens einzelne Stellen flimmern sah) und Hoyer's (27) gegenüber. Letzterer nahm freilich wohl noch in demselben Jahr seine Behauptung, die reg. olf. flimmere, zurück, wollte aber von der Aufstellung besonderer Riechzellen nach wie vor nichts wissen. Balogh (2) beobachtete Härchen, die sich aber nicht bewegen konnten, weil sie in dicklichen Schleim eingebettet waren.

1) Dagegen will Dogiel spïter zn wicderholten Malen beim Hecht und Frosch auf Isolationspräiparaten einen Zusammenhang der Riechzellenfussenden mit centralen Nervenbündeln gesehen haben! 
Clarke (9) erkennt zwar die Riechzellen beim Frosch und den Fischen an, findet aber, dass beim Säugethier die Gebilde der regio olf. alle wesentlich gleichartig seien und hält die Epithelzellen für die Enden der Riechnerven. Gastaldi's (23) wunderbare, von Niemandem getheilte histologische Auffassung der Riechschleimhaut ist nicht der Erwälmung werth, sie ist bei M. Schultze citirt zu finden.

M. Schultze erklärte die Ansicht Clarke's und Balogh's für irrthümlich, die bei Anwendung richtig dosirter Chromsäinrelösungen ohne Weiteres als falsch sich nachweisen liesse. Der Frosch, giebt er zu, besitzt wohl einen Besatz aus feinsten 0,04" langen Haaren; dieselben, nur auf den Riechzellen sitzend, unterscheiden sich aber hinsichtlich ihrer langsam wogenden Bewegung (einzelne Haare sind völlig starr) durchaus von den $8-10 \mathrm{mal}$ kürzeren gewöhnlichen, in dem bekannten schnellen Tempo nickende Bewegungen ausführenden Flimmerzellen der übrigen Respirationsschleimhant. Auch zerstört Wasserzusatz sofort diese Härchen (der Frosch bringt nämlich selbst unter Wasser nie seine Riechgegend mit dem feuchten Element in Berührung, sondern schliesst seine Naslöcher durch Klappen!) und Zusatz von verdünnten Alkalien (Kali-Natronlange) veranlasst nicht etwa wierler Flimmerung. Auch eine stärkere und schwächere Chromsäurclösung als $1 / 5-1 / 6$ Gran auf 1 Unze Wasser (bei Warmblïtern $1 / 8-1 / 16$ Gran auf 1 Unze) vernichtet den Härchenbesatz. Die Riechhärchen kommen Amphibien und Vögeln zu, fehlen aber Fischen, Säugethieren und dem Menschen. Dennoch constatirte aber Schultze an gehärteten Präparaten kleinste 0,001 bis $0,002^{\prime / /}$ lange stäbchenförmige Gebilde anf der Riechoberflüche, die durch eine schwache Querlinie vom Zellfortsatz abgrenzten und sich hier leicht ablösten (1856!). In seiner grösseren Monographie über die reg. olf. indess (1863) leugnet Schultze (ら̆9) (pag. 57) jede Spur eines Wimperbesatzes bei Süugethieren und konnte auch eine vom Zellinhalt scharf abgesetzte Membran nicht nachweisen, "die freie Fläche der Zellen veränderte sich durch Hervorquellen tropfenartiger Inhaltsmassen, Erscheinungen, die bei Berührung mit Wasser viel schneller eintraten." In frischem Znstande erschien die Oberfläche ganz glatt und nicht, wie Balogh annähme, mit Schleim überzogen." Auch die in den Würzb. Verhandl. Bd. V, 1855, p. 17 gegebenen Berichte über die Ge- 
ruchsschleimhant eines Hingerichteten, muss Schultze für eine Täuschung erklären, ebenso wie er A. Ecker's Beobachtung eines Flimmerbesatzes an der reg. olf. eines Justificirten bemängelt resp. sie dadurch erklärt, dass thatsächlich in der gewöhnlich als regio olf. bezeichneten Gegend flimmernde Inseln gewöhnlichen Epithels vorkämen, dass aber ebenso zweifellos die obersten Parthien der Nasenhöhle (am Septum und der obern Muschel) ohne Härchenbesatz wären. Andererseits begegne man auch tiefer unten zwischen dem flimmernden Epithel wimperlosen Stellen. Sonach bedürfe die von Scarpa, Sömmering, Arnold u. A. gegebene Beschreibung von der Ausdehnung und Begrenzung der Geruchsgegend nothwendig einer Correctur. Als Gegenstiick zu den oben angeführten Befunden von Gegenbaur, Leydig und Ecker führt er seine Befunde bei 3 Erwachsenen an, in denen die respiratorische Nasenschleimhant noch 48-60 Stunden p. m. Flimmerbewegung zeigte, wo indess die obersten, dazu noch mit gelb pigmentirtem Epithel besetzten Stellen der Nasenhölle eines Wimperbesatzes entbehrten. Uebrigens habe ja Ecker bei einem nenen Fall den Flimmerbesatz an der saturirt gelben Stelle der obern Nuschel und des Septums ihr gegeniiber auch vermisst. Allerdings, führt .M. Schultze fort (う), können Chromsäurepräiparate gelegentlich zu Trugschlüssen verfïhren. In einem der von ihm beobachteten Fälle zeigte nämlich ein sehr frisches, einem Neonatus entstammendes Präparat, welches za stark erlürtet war, eine grössere Anzahl feinster (durch das Reagens verursachter, M. Schultze!) verschrumpfter und verbogener Härchen auf der Oberfläche. Controllpräparate frisch in humor aqueus von demselben Object angelegt, bewiesen, dass die scheinbaren Haare nur zwischen den Epithelzellen hervorgequollene Fortsätze der Riechzellen waren. Weiterhin sucht er der Ansicht entgegenzutreten, der zufolge die Ausdehuung der Geruchsgegend sich an die schon makroskopisch pigmentirten Stellen hielte. Ecker's locus luteus, der am Septum auf ca. $9^{\prime \prime \prime}$, an der obern Muschel auf ca $4^{\prime \prime \prime}$ und in sagittaler Richtung auf $11_{2}^{\prime \prime \prime}$ Distanz sich erstrecke, entspräiche durchans nicht dem thatsächlichen Verbreitungsberirke des olfactorius, offenbar walteten sehr verschiedene individuelle Verhältnisse vor. Nach Studien am Neonatus würde sehwerlich der untere Rand der oberen Muschel je von einem Riechnervenzweige erreicht. 
Einen Zusammenhang zwischen Olfactoriusendigungen und Riechzellen hält Schultze für höchst wahrscheinlich, die Drüsen nennt er langgestreckte, in der Mitte zwischen Schlanch- und acinösen Drüsen stehende Gebilde. Beim Neonatus ähneln sie sehr denen der Säugethiere.

Welcker und Luschka fanden Flimmern auf der reg. olf. Bemerkenswerth ist aber, dass sich die Flimmern in dïnner Chromsäure nicht halten, denn sie fehlten in dem 2 Tage später angefertigten Präparat.

Frey, der 18652 Std. p. mortem die Riechschleimhant eines 30jährigen Enthaupteten untersuchte, fand die Zellen der reg. olf. in nicht unbeträchtlicher Ausdehnung wimperlos.

Waldeyer wiederum präsentirt noch 1883 auf der VIII. Wanderversammlung der südwestdentschen Neurologen in Baden Prïparate von der Riechschleimhaut eines Hingerichteten mit wohl entwickeltem Flimmerepithel. Freilich schienen damals Herrn Prof. Wald e y er zwischen den flimmernden Stellen auch flimmerlose sich zu befinden, bei genanerer Betrachtung liessen sich aber doch wenigstens noch Reste von Flimmern nachweisen, solass der Vortragende meinte, der ursprïnglich vorhanden gewesene Flimmerbesatz wäre bei den mikroskopischen Manipulationen verloren g.egangen. Waldeyer neigt deshalb der Ansicht zu, die reg. olf. des Menschen besässe einen Flimmerüberzug. Theorie.

Retzius (56) bestätigt für Myxine glut. M. Schultze's

Paschutin (47) fand (beim Frosch) die Riechschleimhaut an den centralen Stellen der reg. olf. 4 Mal so dick, als an den mehr peripher gelegenen. Auch er kann sich von der grundsätzlichen Verschiedenheit beider Zellarten iiberzengen und betont, dass die äusserste Schicht der reg. olf. nur die peripheren Fortsätze der Stüt\%- und Riechzellen trüge. Dann, so fährt er fort, folgt eine Zone ovaler sich stärker färbender Kerne, die meist in gleicher Höhe liegen und den Stützzellen angehören, während die Zone der schwächer gefärbten runden Riechzellenkerne sehr an Breite schwankt, an der Peripherie der Schleimhaut nur aus 1-2 Schichten besteht, im Centrum aber mehr als 15 übereinanderstehende Reihen aufweist. Von der pigmentirten, gefüssreichen, bindegewebigen Schicht erheben sich Capillarschlingen bis in's Epithel. Das Pigment der subepithelialen Zone durchzieht mit 
2 Streifen, einem parallel und nahe dem Epithel gelegenen und einem tiefer mehr gruppenweise verstreuten Antheil die Riechgegend. Die säckchenförmigen Bowmann'schen Drüsen liegen entweder ganz im Epithel oder reichen mehr minder tief in die Epithelschicht, sind aber jedenfalls mit einer kernreichen, zarten Cuticula versehen (M. Schultze konnte sich von einem Drüsenbasalsanm nicht überzeugen!). Im wesentlichsten Punkte, in der grundsätzlichen Differenz zwischen Riech- und Stützzellen ist P aschutin ganz M. Schultze's Ansicht, der sich weiterhin Martin (45), Langerhaus (38), v. Brunn (5), Ciroff (8), Colasanti (10), Peregaslawzeff (48-49), Sidky (62), Löwe (40), Felisch (20), Krause (37) und Dogiel (11 a) anschliessen. In scharfem Gegensatz zu M. Schultze steht Exner (17-19), der einmal eine Reihe von Uebergangsformen zwischen Stütz- und Riechzellen fand, andererseits aber besonders auf Grund von Elgebnissen nach Durchschneidungen des bulb. olf. sich nicht in der Lage sah, M.Schultze's Theorie bestätigen zu können. Er hält beide Zellformen für functionell gleichwerthig und behauptet, dass sich die Nerven an der oberen Grenze des Bindegewebslagers in ein breitbalkiges Netzwerk auflösten, in dessen Lücken Kerne lägen. Aus diesem subepithelialen Maschenwerk gingen, auf keine Weise von ihm abgegrenzt, die centralen Fortsätze der Epithelzellen hervor ebenso wie die centralen Fortsätze der Riechzellen. Typische Riechzellen im Sinne Schultze's fand Exner nicht olne Weiteres, wohl aber (Kaulquappe) den ersteren morphologisch sehr nahe stehende Elemente. Das normale Vorkommen von Uebergangsformen zwischen Riech- und Stiutzzellen, sowie die gleichmässige Degeneration beider Zellformen nach Durchschneidung des n. olfactorius, endlich der Zusammenhang der Nervenfasern mit beiderlei Zellenarten, lassen ihn $\mathrm{zu}$ der alten Ecker'schen Ansicht zuriickkehren, der zufolge man die von Eckhardt beschriebenen spindelförmigen Zellen (M. Schultze's Riechzellen) als einfache Ersatzzellen d. h. sich entwickelnde Epithelzellen anzusehen habe.

Ausser Exner sahen auch Grimm (24-25), Lustig (43) und Peregaslawzeff (48) Uebergangsformen, Föttinger sogar nur Epithelzellen. Remy fand nur einen Zusammenhang zwischen Epithelzellen und Olfactoriusfasern. Das subepitheliale Netz wollen auch Paschutin (47) und Peregaslowzeff (48) gesehen haben, 
Beiträge z. feinern norm. Anat. d. mensehl. Geruchsorganes. 381

während Löwe (40), Ciroff (8), Colasanti (19), v. Brunn (5-6), Retzius (56) und Schultze ihm jeden nervösen Character absprechen und es für bindegewebig erklären.

Dirknik-Holmfed (10a), der Exner's Versuche wiederholte, sah nach Durchschneidung der bulbi olfactorii beim Frosch 3-4 Wochen später bereits die ersten Degenerationserscheinungen an den Riechzellen, während die Stützzellen erst 3-4 Monate post operationem entarteten. Er steht somit auf M. Schultze's Seite.

In den letzten Jahren ist man nun auch auf entwicklungsgeschichtlichem Wege der Frage von der Specificität der Zellen der reg. olf. näher getreten, Untersuchungen, die aber ein mehr für Exner's Auffassung sprechendes Resultat ergeben haben. Ich nenne hier nur $\mathrm{Putelli,} \mathrm{der} \mathrm{Uebergangsformen} \mathrm{zwischen}$ Riech- und Stïtzzellen konstatirte.

Nach Kaufmann (31) ist es der Einfluss der Reagentien, der nach einer gewissen Zeit zur. Bildung verschiedener Zellformen führt. Kanfmann studirte längere Zeit die Veränderungen der Rachenschleimhaut in bestimmten Zusatzflüssigkeiten. Hierbei will er direct beobachtet haben, dass die von M. Schultze als Riechzellen bezeichneten Gebilde sich unter Ausstossung feinster Pigmentkörnchen direct aus den Stiitzzellen herausbildeten. Bei Anwendung indifferenterer Lösungen fand er theils Epithelzellen, theils kolbenartig oder mehr minder konisch zugespitzte Elemente. In der Ueberosmiumsäure prävalirte der Typus der Riechzellen. Bei Anwendung der sofort fixirenden 3procentigen Salpetersäure sind ausgesprochene Riechzellen viel seltener. Somit sind die sogenannten Riechzellen Abkömmlinge der Epithel(Stütz-)zellen und der Widerspruch in den einzelnen Ansichten erklärt sich durch die mehr minder langsame oder intensive Einwirkung der Agentien. - Bei Anwendung riechender Stoffe gelang es ihm aber nicht, Riechzellen aus Epithelzellen zu erzeugen.

Aus dieser historischen Uebersicht, die nur die Hauptpunkte der uber den mikroskopischen Bau des Riechepithels herrschenden Differenzen wiedergiebt, geht zur Genüge hervor, dass eine erneute Bearbeitung des Gegenstandes und zwar unter Benutzung der heutzutage so hoch entwickelten Technik für nicht überflüssig zu erachten ist. Am ehesten glaubte ich mit Hülfe vergleichend anatomischer Studien zu einer präciseren Anschanung uiber die 
regio olfact. zu gelangen und dies ist der Grund, der mich seit 2 Jahren zn zahlreichen Untersuchungen von Amphibien, Sïugethieren und Mensch veranlasste.

Von Untersuchungsmethoden musste ich die von M. S chultze empfohlenen Isolationsmethoden in erster Linie berïcksichtigen. Am schnellsten wirkt Kalilauge von 30-40 Procent Kali anhydric. $(1 / 2-1$ Stunde), langsamer (1-3 Tage) Chromsäurelösungen (Kaltbliiter $0,04-0,033 \%$, Säugethiere $0,05-0,03 \%$, Menseb $0,05 \%$ ) eventuell unter Zusatz von etwas Gummischleim, Lösungen von Kali bichromic. $(0,2-0,8 \%)$ und Müller'sche Flüssigkeit allein oder mit physiologischer Kochsalzlösung. Zur Controlle diente Ranviers $1 / 3$ Alcohol allein oder mit nachfolgender Osmiumbehandlung $(1 \%$ ) nach Stöhr, oder Osmiumsiüre allein 0,025\% (mehrere Tage) bis 1procentige Osmiumlösungen (24 Stunden). Endlich machte ich einen Versuch mit Ausstrichsprïparaten, die ich mit $7 \%$ Sublimat fixirte.

Auch die Kaufmann'schen Untersuchungen bemühte ich mich zu wiederholen, muss aber gestehen, dass seine Methocle der halbflüssigen Beschaffenheit des frischen Epithels halber recht schwierig ist. Man kann die Epithelien nicht von einander trennen ohne Kunstprolucte zit erzeugen, frisehe Sehnitte fallen zur Erkennung feinercr Details zu dick aus und wollte man sich des Gefriermikrotoms bedienen, so miisste man auf die vitalen Erscheinungen des firischen Gewebes verzichten (event. Flimmerbewegung).

Allerdings kamn man an feinsten mit gebogener Iridectomiescheere entnommenen Partikelchen, falls man den Rand des Präparats einstellt, bei Thieren die reg. olf. von der reg. respiratoria der enorm differirenden Höhe des Epithels halber unterscheiden und sich ein Urtheil iiber Fehlen oder Bestehen eines Flimmerbesatzes bilden, beim Menschen ist eine solche Scheidung. allein nach der Höhe nicht zulässig, weil mitunter das Epithel der reg. respir. das der reg. olf. an Dicke überragt, andererseits die bei Thieren in 12 facher Lage übereinanderliegenden Riechzellenkerne beim Menschen einen viel geringeren Raum beanspruchen, wozu noch mannigfache durch Metaplasieen verursachte Anhäufungen von Zellen (resp. Kernen) in den unteren Lagen des respirat. Epithels kommen, die letzteres dem Geruchsepithel sehr ähnlich machen. Rechnet man hierza noch die gar nicht so seltenen Wanderungen ron Leucocyten durch's Epithel (wie sie 
von Stöhr in der reg. respir. bereits nachgewiesen sind und von mir auch in der reg. olf. beobachtet wurden), die, wenn sie massenhaft erfolgen, den Charakter des Epithels in dicken Schnitten ganz vernichten können, so dass man nur unter Zuhülfenahme feinster Paraffinschnitte ins Klare kommt, so wird man begreifen, dass Irrthümer sehr leicht unterlaufen können ${ }^{1}$ ).

Ich - kann daher nicht sagen, dass mich die nach Analogie von Kaufmann fortgesetzte längere Untersuchung frischer Objecte zu demselben befriedigenden und bestimmten Resultat gefiuhrt hat, wie es ersterem gelungen ist. Austritt von Pigmentkörnchen erfolgt sehr bald aus den Firsten der Epithelzellen und auch eine Einwirkung selbst indifferenter Lösungen anf die Epithelzellen glaubte ich annehmen zu dürfen, indess zu einem bestimmten Urtheil ïber die verschiedene Dignität der Zellen wïrde ich mich allein auf Grund dieser difficilen Methode nie veranlasst sehen. Wohl aber schien mir die häufige Wiederholung frischer Untersuchungen zur Feststellung event. bestehender Flimmerung indicirt und ich habe desshalb, als ich meine Untersuchungen an der Riechschleimhaut des Kalbes, des Ochsen und am Sehwein vornahm, die Präparate an Ort und Stelle, d. h. im Schlachthof entnommen und daselbst in humor aquens resp. 0,73procentiger Kochsalzlösung untersucht. Die Partikelchen wurden den hintersten Theilen der gelb bis bräunlich gefärbten Ethmoidalwülste nach sagittaler Aufsägung des Schädels mittelst feinster Scheere entnommen und zwar an derjenigen Hälfte, die noch von der Nasenscheidewand bedeckt war ${ }^{2}$ ). Durch kleine Paraffintröpfchen, die auf den Objectträger aufgekittet waren, wurde das Präparat vor übermässigem Druck seitens des Deckglases (resp. eines noch leichteren Glimmerplättchens) geschützt. Ich habe ein Mal unter 20 Malen auf der Oberfläche von anscheinend typischem

1) Selbstredend ist es durchaus nicht meine Absicht, den Werth der frischen Präparate von der menschlichen reg. olf. schmälern zu wollen, dieselben sind ja namentlich bei Beurtheilung pathologischer Vorgänge (namentlich von Verfettungen) unentbehrlich, indess ohne Anlegung von Schnittserien kann man sich keine vollständige Vorstellung von dem Bilde einer menschlichen Geruchsgegend machen.

2) Da beim Aufsägen des Schädels das Sägeblatt oft unerwartete, erst bei der mikroskopischen Untersuchung hervortretenden Lisionen schafft. 
Geruchsepithel sich bewegende feinste Härchen gesehen, möchte aber doch mit Rücksicht anf die vielen negativen Resultate dieser einen Beobachtung keinen besonderen Werth beimessen, zumal mich die weitere Verfolgung meines Thema's mittelst Schnittserien M. Schultze's Ansicht genähert hat. Anch beim Kaninchen und Meerschweinchen gelang es mir nicht, in frischen Objecten Flimmern nachzuweisen, wohl aber beim Frosch, dessen regio olf., wie M. Schultze selbst zugiebt, mit langen feinen, in langsamem Tempo schwingenden Haaren besetzt ist. - An Paraffinschnitten durch die Riechgegend der genannten Thiere indess ist ein Besatz feinster Härchen, die etwa nur 1/2 Mal so hoch sind als die Flimmern der reg. respir. unschwer zu erkemnen. Auch an der reg. olf. der Maus wurde der Härchenbesatz nicht vermisst. Nichtsdestoweniger nehme ich Anstand, ihn mit gewöhnlichem Flimmerüberzug zu identificiren, denn sowie der Härchenbesatz auf der Ricchschleimhaut des Frosches etwas durchaus Eigenartiges von gewöhnlichem Flimmerbesatz Verschiedenes darstellt (ef. oben), so muss auch dem Besatz auf der reg. olf. der Säugethiere ob seiner Küræze, Feinheit und leichten Zerstörbarkeit eine ausgesprochene Originalität zuerkannt werden. Die Härchen sitzen dem Epithel in seiner ganzen Continuität auf, es ist aber mir mehr wahrscheinlich, dass sie nur den Riechzellen zukommen, nur sind letztere in so überwiegender Mehrheit vorhanden, dass sie die Stützzellen selbst auf feineren Schnitten verdecken. Ich kann also M. Schultze's Ansicht über die ganz glatte Beschaffenheit der Geruchsschleimhautoberfläche nicht theilen, will aber zugeben, dass der Härchenbesatz mit gewöhnlichen Flimmern nichts zu thun hat ${ }^{1}$ ).

Im Uebrigen muss ich mich als Anhänger der Schultzeschen Lehre von der Specificität der beiden Zellarten bekennen. $E_{s}$ ist an Schnitten durch langsam erhärtete (Müller's Flüssigkeit, dünnere Chromsäurelösungen) Präparate unschwer sich ein Urtheil über die verschiedene Form und die verschiedene Farbennüance (Färbung mit Delafield's Hämatoxylin, Contrastfärbung des Protoplasmas durch Eosin oder Congo) der Kerne der sogenannten Stützzellen und Riechzellen zu bilden. Die Stützzellen-

1) Danach ist meine frühere Ansicht, dass die regio olf. sämmtlicher Thiere und des Menschen flimmern, einer Korrektur bedürftig. 
kerne sind oval und tiefer blau, die Riechzellenkerne rund und blässer. Dieses Verhalten ist bekannt, nur scheinen mir die Angaben über die Form noch einer Erweiterung bedürftig. Ich habe nämlich durch Vergleichung früher und später eingelegter Objecte und Anwendung schneller und langsamer erhärtender Reagentien (Chromessigsäure, 7procentige Sublimatlösung) von der Riechschleimhaut des Hundes Bilder erhalten, in denen nur ein Theil der Präparate diese auffallende Formdifferenz zeigte, in anderen Präparaten waren auch die Stützzellenkerne mehr rundlich. An Sublimatpräparaten gelang es auch, die Kernstruktur gut zu erhalten, und wenn es mir auch Anfangs nicht gelingen wollte, wesentliche Unterschiede im Bau des Kerns herauszufinden, so schienen mir doch in einem besonders schnell und gut 11 Ethmoidalmuschel auf 1 Liter 7 procentige $40^{\circ}$ warme Sublimatlösung 3 Minuten p. mortem eingelegt) fixirten Object von der Riechschleimhaut des Ochsen Differenzen der Kernstruktur zu bestehen. Während die (übrigens in der Form den Riechzellenkernen fast gleichenden) Stützzellenkerne mehrere kleine Nucleoli enthielten, besassen die meisten Kerne der Riechzellkernzone einen grösseren, meist etwas excentrisch gelegenen Nucleolus, wie er Ganglienzellen eigenthümlich ist.

Unbekannt ist ferner die verschiedene Resistenz des Kerninhalts gegen Temperaturerhöhungen und höherprocentige Kali bichromicumlösungen. Wenn man auf Deckgläser oder Glimmerplättchen aufgeklebte Paraffinschnitte ïberhitzt und systematisch $\mathrm{zu}$ verschiedenen Zeiten, bei verschiedenen über $56-58^{\circ} \mathrm{C}$. liegenden Temperaturgraden untersucht, so wird man finden, dass schon verhältnissmässig früh das Chromatin der Riechzellenkerne chemisch sich ändert, dass eine Art von (der Coagulationsnecrose im Aussehen ähnliche) Necrose eintritt, die dem Kern sein Färbungsvermögen raubt, während die Stützzellenkerne noch recht gut Hämatoxylin annehmen. Rechnet man hierzu noch die variköse Beschaffenheit der centralen Enden der Riechzellen und berücksichtigt man den Umstand, dass die grössere Dicke der Riechschleimhaut osmatischer Individuen (Hunde, Kaninchen) gegeniiber der sehr viel geringeren Dicke der anosmatischen Thiere (Affen, Mensch) wesentlich auf die Differenz der sogenannten Riechzellenkernzone zu schieben ist, so wìrd man keine Veranlassung haben, M. Schultze's Theorie mit einer anderen zu vertauschen. - 
Doch ohne mich auf weitere Details der thierischen reg. olf. einzulassen, erlaube ich mir, meine Ergebnisse beim Mensehen zu schildern.

Während die mit hellgelber bis bräunlicher Schlcimhaut bedeckten Ethmoidalmuscheln der meisten Sängethiere ${ }^{1}$ ) eine geradezu wunderbare Ausbildung und Faltung zeigen, springt beim Menschen das Siebbein nur in Form zweier Wuilste in die Nasenhöhle vor. Dieselben, nach dem Schädel durch die lamina cribrosa abgeschlossen, repräsentiren die grössere, mittlere und kleinere über ihr oder etwas mehr hinter ilır liegende obere Muschel, die von ersterer durch einen von hinten hereindringenden Spalt getrennt ist. - Die obere Muschel wird häufig durch eine zweite Fissur. ethmoid. getrennt; dann enthält das Siebbein 3 Muscheln, wie es beim Neugebornen die Regel ist ${ }^{2}$ ). Zuweilen kommt anch noch an der horizontalen Partie der mittleren Muschel ein Spalt vor dann existiren auch beim Menschen 4 Riechwiilste.

Zur Entnahme von Schleimhautstïcken ist natïrlich die Halbirung des Schïdels am vortheilhaftesten. Mir standen halbirte Schädel indess nur von Neugeborenen zur Disposition und da auch an anderen anatomischen Austalten im Allgemeinen es schwicrig sein diurfte, frisehe halbirte Schädel zu erhalten, muss man versuchen, sich den Zugang zur Nasenhöhle vom Munde her nach Durchsägung des Alveolarfortsatzes zu verschaffen oder, was viel beqnemer ist, von der oberen Fläche der Schädelbasis her einztdringen suchen. - Zu diesem Behuf wird mit dem Meissel oder der Stichsägre das Siebbein aus seinen Verbindungen gelöst; es ist zweekmässig, sich immer wenigstens ca. $1 \mathrm{~cm}$ von dem Rande der lamini cribrosa entfernt zu halten, vorne dicht vor der crista galli durchzumeisseln, nach hinten zu aber den grössten Theil des Keilbeinkörpers mitzunehmen. Auch vom sept. narium kann man sich durch schräges Aufsetzen des Meissels ein recht grosses Stiuck verschaffen. Wo Meissel und Säge nicht ausreichen, muss

1) Nur die Primaten zeigen nach $Z u$ ckerkandl einen einfachern, dem des Menschen ähnlichen Bau des Geruchsorgans, der als Rückbildungsvorgang aufaufassen ist.

2) Diese Thatsache liisst in M. Schultze's Angaben über die obere Muschel des Neugeborenen und die Ausbreitung des N. olfactor. die nöthige Deutlichleit vermissen; man weiss nicht, ob Schultze den untern Rand der dritten oder vierten Muschel meint. 
eine Knochenscheere nachhelfen. So erhält man mit dieser anfänglich etwas roh erscheinenden, aber - gute Instrumente und einige Uebung vorausgesetzt - völlig zum Ziel führenden Methode die obere und mittlere Muschel, jedenfalls also das Terrain der reg. olf. - Die untere Muschel und Schleimhautstiicke ans dem Nasenboden und den Nasenhöhlen sind hinterher leicht zu erhalten. Nach Herausnahme des Siebbeines wird clie lamina cribrosa mit einer Laubsïge eingekerbt, so dass sich obere rnd mittlere Muschel leicht vom Septum abbiegen und beliebige Stücke der Schleimhaut entnehmen lassen.

Ich wählte entweder die ganz oberste Partie des sept. narium oder Theile von ihr, ferner Stïcke von der medialen Fläche der oberen Muschel ${ }^{1}$ ) und fertigte horizontale und vertikale Schnitte an. Sehr vortheilhaft erșchien es mir, die Schleimhaut von der lamin. cribr. an bis zum unteren Rande der mittleren Muschel in continuo abzuheben und vertikale Schnitte dureh diesen Theil der Nasenhölle anzulegen. Ich durfte so sicher erwarten, reg. olf. und respir. in einem Schnitt zu erhalten. - Das Abhebeln der Schleimhaut, welches mit einem dünnen, vorne scharfen und abgerundeten, elevatoriumartigen Messer vorgenommen werden kann, gelingt sowohl am frischen Präparat als am gehärteten. Das frische Prïparat wird mit Igelstacheln auf eine Korkplatte geheftet und dann in Sublimat gehärtet. Ich habe indess gefunden, dass es besser ist, von dem gehärteten Präparte Stüicke zu entnehmen. Es geht das ebenso gut, man ist nicht in solcher Gefahr, Epithelverluste zu erhalten, kann einzelne Regionen in Musse studiren, ohne Verwechselung der Stückchen riskiren zu müssen. Wichtig ist es aber, vor dem Einlegen der Schleimhautstiicke in Celloidin oder Paraffin jeden Rest von, dem Präparat eventuell auhaftenden Knochenblättchen zu entfernen. Bekanntlich verlaufen die Olfact.Fasern in Knochenrinnen oder Scheiden, $j a$ es dringen mitunter kleine Einscheidungen etwas höher in die Schleimhaut hinauf. Am Septum ist die Ablösung: ungleich leichter als an den Muscheln, besonders schwer am unteren Rand der mittleren Muscheln. Unbequem ist das genaue Registriren der einzelnen Stiickehen aus den verschiedenen Gegenden der reg. olf., es ist aber unerlïsslich

1) Es ist wichtig, sich immer auf die mediale Hilfte der obern Muschel zu beschrinken. 
und von mir strikte durchgeführt. - Wie für M. Schultze, war auch für mich der Ausgangspunkt weiterer Untersuchungen die reg. olf. des Neugeborenen. Auf genau nach M. Schultze's Angaben vorgenommenen Isolationspräparaten $(0,005 \%$ Chromsäurelösung) constatirte ich die von M. Schultze genügend charakterisirten beiden Zellformen, indess war bei einzelnen Riechzellen das periphere Ende mehr stälschenförmig, andere entsprachen mehr den schon von Anderen beschriebenen Riechzapfen und Riechkolben (Dogiel (11a) sah auch beim Frosch ähnliche Formen). Ausser diesen Gebilden und den an der Basis des Epithels gelegenen sternförmigen Ersatzzellen fand ich aber noch zum Theil runtliche, zum Theil ovale Zellen, die mitunter an einer Seite etwas konisch zuliefen. Ich hielt sie für Kunstprodukte, bis mich Serienschnitte eines Andern belehrten. In feinen Paraffinschnittserien (jeder Schnitt $1 / 200 \mathrm{~mm}$ dick und dünner) lässt sich die Verschiedenheit des respiratorischen und des Geruchsepithels ohne Weiteres erkennen. Während man es an der unteren Muschel, am Naseuboden und den unteren Partien des sept. narium mit einem einschichtigen $0,045 \mathrm{~mm}$ hohen Flimmerepithel zu thun hat (Flimmern 0,006 mm lioch), erreicht schon im Bereich des unteren Theiles der mittleren Muschel das Epithel die Höhe von 0,06 mm und wird auf der 3. und 4. Muschel 0,075-0,081 mm hoch. Man unterscheidet an dem von feinsten, nur $0,003 \mathrm{~mm}$ hohen Hürchen bedeckten Epithel ${ }^{1}$ ) einen peripheren, 0,015-0,024 mm hohen

1) Ueber die Bedeutung des feinen Besatzes auf den Kuppen des Riechepithels ist viel gestritten worden. An ganz frisch fixirter thierischer Riechschleimhaut erscheint der Besatz streckenweise thatsächlich aus feinsten Stäbchen zu bestehen und wird dadurch dem Cuticularsaum des Darmes sehr ähnlich, an andern Stellen aber differenzirt er sich als feinster Härchenbesatz. An noch andern Stellen, wo unbewusste und unbeabsichtigte Verletzungen bei den verschiedenen Manipulationen mit dem Präparat entstanden, erscheint die Oberfliiche ganz glatt. Dasselbe Phänomen beobachtet man an möglichst frisch eingelegter Riechschleimhaut. Ich glaube die Differenz in dem Aussehen der einzelnen Stellen dadurch erklären zu können, dass ich eine Verklebung der Härchen durch die, die Oberfläche stets überziehende dünnste, von den Drüsen (oder Zellen?) abgesonderte Serumschicht annehme, wodurch allerdings bei Sublimatfixation ein Cuticularsaum vorgetiiuseht werden kann. Davon völlig verschieden sind die postmortal aus den Zellen austretenden Eiweissfiiden, -flocken und Tropfen. 
Protoplasmasaum, der dem Ende der Stütz- und Riechzellen entspricht und daher vertikal gleichmässig gestreift erscheint (namentlich schön in Gummiglycerinpräparaten [Hoyer] und Glyceringelatine [Klebs]). In seinem Bereich präsentiren sich einzelne Kerne und Zellen mit Kern- and Protoplasmaring, Gebilde, wie sie den in den Isolationspräparaten für Kunstproducte gehaltenen entsprechen. Der grösste Durchmesser der Kerne beträgt 0,009 mm, das Protoplasma umgiebt den Kern mitunter auch in Form eines Halbmondes oder krönt ihn als konisch geformten Aufsatz, so dass Zelle und Kern zusammen einen vertikalen Durchmesser von $0,015 \mathrm{~mm}$ zeigen. - Auch mit querovalem, 0,006 mm hohem und rundem, 0,006 mm im Durchmesser haltendem Kern versehene Zellen wurden gefunden. Diese Zellen, die mit den Stiitzzellen nichts zu thun haben und auch nicht etwa den Drïsenausfïlnrungsgängen angehören (die Kerne der Drüsenausführungsgänge sind meist oval, die Zellen selbst vertikal in die Länge gezogen), sind nicht spärlich vorhanden; ich zählte auf einem Schnitt von $2,25 \mathrm{~mm}$ Länge deren 43. Diesem Protoplasmasaum schliesst sich die Zone der Stuitzzellenkerne an. Die Durchmesser dieser mehr ovalen Kerne betragen 0,0045:0,009-0,012 mm. Dann folgt die breite Zone der Ricchzellenkerne, die hauptsäehlich der reg. olf. ihr eigenthïmliches Aussehen verleiht, so dass man unwillkürlich zu einer Vergleichung mit der Retina gedrängt wird. Man kann etwa 5-6 Kermreihen unterscheiden und betragen die Durchmesser der eiuzelnen Kerne 0,006:0,0075 mm oder 0,006: 0,009 mm, doch kommen hier auch mehr ovale Kerne mit den Durchmessern 0,006:0,00975 mm vor. Ich habe schon oben den Grund der Abweichung in der Form des Kernes hervorgehoben.

Ueber die zwischen den Basalenden der Epithel- und Riechzellen befindlichen Ersatzzellen, die sich vorzüglich durch ihre $0,006 \mathrm{~mm}$ breiten Kerne kennzeichnen, ist nichts Besonderes zu sagen. Eine die Fussenden der Epithelzellen von der tunic. propr. trennende Cuticula ist beim Neugeborenen nicht nachzuweisen. Die Bowman'schen Drüsen entsprechen dem Typus der leicht verässtigten tubulösen Drüsen und sondern Serum ab, während die in manchen Lehrbüchern fälsçlich als acinöse Drïsen bezeichneten Gebilde der respir. Gegend zusammengesetztere tubulöse, 
theils Schleim, theils Serum absondemde Drïsen darstellen ${ }^{1}$ ). Die Drüsen der reg. olf. reichen an verschiedenen Stellen mit ihrem kolbigen Ende (Drüsengrund) bis aufs Periost, der Drïsenausführungsgang im Epithel ist meist sehr schmal, manchmal aber auch $0,009-0,012 \mathrm{~mm}$ breit. In der subepithelialen Zone sind je nach der Erfüllung mit Sekret die Drtisenkörper 0,021 bis $0,03 \mathrm{~mm}$ breit. Wo die Drïsenwände auf einander liegen, entspricht der Durchschnitt eines Tubulus einem Durchmesser von $0,024 \mathrm{~mm}$. Beim Eintritt ins Epithel verschmälert sich der Ausführungsgang rasch. Die Drüsenzellen sind meist kubisch, seltener kleincylindrisch, der iibrige Theil der subepithelialen Schicht wird von spürlichem adenoiden, mit elastischen Fasern untermischtem Gewebe eingenommen, in dem je nach der Schnittrichtung bald Quer-, bald Längsschnitte der marklosen Riechnerven bemerkbar werden. - Das bei Thieren so deutlich im basalen Theile des Epithels, sowie in dem peripheren protoplasmatisehen Saum, endlich in den Driisenzellen angehäufte Pigment ist beim Neonatus a uf Schnitten sehr wenig ausgeprägt, ja in Balsampräparaten vielfach gar nicht sichtbar. Wohl aber lassen sich pigmenthaltige Zellen zwischen den Drüsen und in der Nähe der Gefässe, sowie in den Olfactorinsscheiden gut nachweisen. M. Schultze erwähnt Pigmentanhänfungen an diesen Stellen nicht und doch ist dieser Befund als physiologische Erscheinumg für die Beurtheilnng mancher Pigmentationen der reg. olf. beim Erwachsenen wesentlich. - Viel besser lässt sich das Pigment beobachten, wenn man das Präparat unmittelbar nach seiner Tinction in Aq. dest. untersucht.

Schon in den ersten Kinderjalren kann sich unter dem Einfluss überstandener Diphtherie, lünger bestehender Katarrhe, wie sie primür, hänfiger aber sekundär im Anschluss an Rachentonsillenhypertrophie, übermässiger Enge der Choanen (cf. Hopman's Arbeit) vorkommen, das oben entworfene Bild mehr minder erheblich ändern, wie sich ïberhaupt schon jetzt eine Einengung und Verschiebung der Grenzen der reg. olf. bemerkbar macht. Schon jetzt können Inseln respiratorischen Epithels auf der oberen

1) Flemming ist bekanntlich fïr eine genauere Klassificirung der Drüsen eingetreten. 
Muschel vorkommen und zu irrigen Deutungen Veranlassung geben. Sehr lehrreich waren mir in dieser Beziehung einige Präparate von $1 \frac{1}{2}$ - 4 jührigen Kindern, die entweder cine Nasendiphtherie überstanden oder einen die Diphtherie begleitenden Nasenkatarrh durehgemacht hatten. Das Epithel war viel niedriger als zu erwarten stand, die Zone der Riechzellenkerne verschmälert, mit nur 2--3 Kermreihen versehen und in clen Driisen befanden sich die Zellen theilweise in Desquamation, ku"\% es handelte sich um die Residnen pathologiseher Vorgänge resp. regenerative Processe. Bei anderen Kindern, die keine pathologische Nasenaffection zeigten, besass das Riechepithel eime Höhe von $0,06-0,069 \mathrm{~mm}$ und enthielt 3-4 Reihen von Ricchzellenkernen. Die oben beim Neonatus beschriebenen, im Protoplasmasaum sich vorfindenden Zellen kommen auch in der Riechschleimhant ailterer Kinder (1-4jährige beobachtet) vor. Bei einem 6jälırigen Knaben begegnete ich ausser diesen Zellelementen auch schon leicht pigmentirten (cf. die weiter unten beschriebenen Glockenzellen) in der Form letzteren ziemlich ämlichen Gebilden.

Ich muss noch 'nachtragen, dass sich makroskopisch die reg. olf. in den beobachteten Fällen entweder gar nicht oder nur an ganz umschriebenen Stellen leicht gelblich gefürbt erwies.

Bei Erwachsenen giebt es Präparate, an denen die Geruchsgegend gleichfalls durch keine besondere Tinction markirt ist, meist ist die Nasenschleimhant gleichmässig rosaroth. Andererseits erweisen sich einzelne Stellen am Dach unter der lamina cribrosa schön orange pigmentirt. Jedenfalls ist auch nur von einiger Regehnässigkeit hinsichtlich der Pigmentirung gar keine Rede. - In einem Falle erwies sich nicht nur die reg. olf., sondern auch die reg. respir. deutlich hellgelb gefärbt, wie ja anch mikroskopisch Pigmentirungen an der mittleren und unteren $\mathrm{Mu}$ schel durchaus nicht zu den Seltenheiten gehören. - Recht häufig. war die untere Hälfte und namentlich der vordere Theil der mittleren Muschel incl. seines unteren Randes schön rostgelb tingirt. - Kurz, aus der Anwesenheit des Pigments hat man kein Recht auf Gegenwart von Geruchsepithel zu schliessen, man ist auf diejenige Lokalität angewiesen, in der sich der reg. olf. verzweigt, das Nasendach unter der lamina cribrosa, die obersten Theile des Sept. gegenüber der oberen Muschel, die mediale Fläche der letzteren und allenfalls die obere Hälfte der mittleren Muschel. 
Viel wichtigere Anhaltspunkte zur richtigen Würdigung der mikroskopischen Befunde durfte man erwarten, wenn es gelang, cin erwachsenes Individuum bei Lebzciten auf scine Riechtïhigkeit hin zn prüfen. Nur einmal hatte ich diese günstige Gelegenheit. Es handelte sich $\mathrm{nm}$ einen 35jährigen Locomotivführer, der an einer doppelseitigen Recurrensparalyse in Folge eines Aneurys. arc. aort. laborirte. Patient erfieute sich scit Jahren eines vortrofflichen Geruchs. Mit dem Zwaardemaker'schen Riechmesser grepriüft ergab sich bei ca. $14^{\circ} \mathrm{C}$, , die Grösse der Olfactie ansgedrüekt in Millimeter: Cylinderlänge des Zwaardermaker'schen Riechmessers für Cedernholz $20 \mathrm{~mm}$, für Kautschuk $9 \mathrm{~mm}$, für Tolubalsam $1 \mathrm{~mm}$. - Dieser Paticnt wurde ca. 18 Stunden p. m. secirt und dis Siebbein, welehes nirgends Pigmentirungen aufwies (nach Exision kleinster Particn ans ler reg. olf. behufs Erlangung. von Macerationspräparaten), sofort in 7procentiges Sublimat gelegt. - Anf Erltaltung der Kernform und -struktur imnerhalb der reg. olf. durfte ich nicht rechnen, nichtsdestoweniger gab das Präparat recht instruktive Bilder.

Nach vollenleter Härtung erwies sich eine circumscripte Stelle der reg. olf. am Nasendach, Septum und den obersten Theilen der oberen Muschel ganz leicht gelblieh verfärbt. Sehnitte aus diesen Gegenden ergaben folgendes Bild: 0,06-0,081 mm hohes, mit feinsten 0,003 mm messenden Härehen besetztes Epithel. Peripherer Protoplasmasaum, 0,021-0,027 $\mathrm{mm}$ hoch, zeigt dieselben Kerne und Zellen, wie ich sie bereits beim Neonatus beschrieb. Ansserdem ist eine Anzahl Stuitzzellen bald verstrent, bald zu Bündehn gruppirt mit grobkörnigem gelben Pigment gefüllt. Die Menge des Pigments variirt, in manchen Zellen ist sie so erheblich, dass lediglich mit gelben Körnchen gefüllte Becherzcllen entstehen. Der Kern dieser Zellen ist entweder ganz wie bei den gewöhnlichen schleimführenden Becherzellen basalwärts gedrängt oder gegen die vordere oder hintere Zellwand (etwa in deren Mitte) gepresst. - Am meisten interessirte mich aber eine Zellform, deren bisher von Niemand Erwähnung gethan war, die in ihrem Aussehen etwa den kleinen kugeligen Glocken ähneln, wie man sie an Pferdeleinen kleiner Knaben sieht. Es sind theils runde, theils etwas längs-, theils querovale deutlich pigmentirte Gebilde, die einen Kern besitzen, der bald oben, bald unten an der Zelle sitzt, oft aber auch an deren vorderer oder hinterer 
Wand zur Beobachtung kommt. Auch Zellen mit zwei dicht neben einander oder diametral gegenüberliegenden Kernen sind stellenweise sichtbar. - Dieser Befund veranlasste mich dazu, den Gedanken, diese Zellen könnten möglicher Weise eine besondere Form von Sinneszellen darstellen, aufrugeben; denn einmal fehlen sie bei Thieren, und dann darf man auf Grund der verschiedenen Lage des Kerns annehmen, dass die Zellen nur in Folge einer Rollbewegung sich in dieser verschiedenen Weise priisentiren, mithin zu weniger sesshaften Gebilden, als es die eigentlichen Simeszellen sind, gerechnet werden müssen. - Hinsichtlich ihrer Herkunft wären zwei Entstehungsmodi ins Auge zu fassen - einmal könnten sic sich aus den stark pigmentirten ausgebautehten Stiitzzellen entwickeln - andererseits aus dem subepithelialen Gewebe, das je eine Reihe von ovalen und rundlichen Pigmentzellen birgt, ins Epithel einwandern. Für den ersteren Entstehungsmodus spricht das Vorhandensein einer Anzahl Uebergangsformen zwischen bauchigen pigmentführenden Stützzellen (ich crinmere an die oben beschriebenen Zellen, bei denen der Kern gegen die andere Zellwand gepresst war) und den fusslosen Glockenzellen, für den zweiten Vorgang das Vorkommen der direkten Kerntheilung, wie sie durchwandemden Lenkocyten eigen ist, sowie die Anwesenheit ähnlicher Zellen in der Tunica propria meist dicht unter dem Epithel. Man muss aber oft lange suchen, bis man derartige ähnliche Zollen unter dem Epithel erspäht.

Um dem Leser von der Art des Vorkommens dieser Zellen einen besseren Begriff zu geben, erlaube ich mir, über einige Serien genaueren Bericht zu erstatten.

Vaterlaus, 30jähriger Mann. Aortenaneurysma serös. Pleuritis, Nasenschleimhaut rosaroth, kein Katarrh. - Obere Muschel, obere Hälfte der medialen Fläche (horizontale Schnitte).

Schnitt I. Riechepithel deutlich, mit Stellen flimmertragenden respirat. Epithels abwechselnd, an dem einzelne Zellen mit Serum, andere mit Schleim erfüllt sind. Nur dort, wo deutliches Riechepithel vorhanden ist, zeigen sich innerhalb des Protoplasmasaumes 2 Glockenzellen, die an ihrem obern Pol einen Kern tragen, dann folgen 2 Glockenzellen mit 1 Kern am untern Pol, dann wieder 1 Glockenzelle mit 1 Kern oben, dann noch う weitere Glockenzellen, die den Kern unten tragen.

Schnitt II. Viel respirat. Epithel, nur wenig gut erhaltenes Riechepithel. Im respirat. Epithel keine Glockenzellen wahrnehmbar, wohl aber 
im Riechepithel eine am Fuss dor Epithelzellen gelegene Glockenzelle. Kern nach oben.

Daun folgt eine Glockenzolle, deren Kern an die vordere (oder lintere!) Zellwand gepresst ist, damn wieder eine Glockenzelle mit einem am obern Pol befindlichen Kern, dann eine undentlich pigmentirte, fast nur den Kern beherbergencte Glockenzelle, endlich noch 1 Glockenzelle mit am oberen Pol sitzenden Kern und noch einige undentlich narkirte, Glockenzellen ahnliche Gebilite.

Der bessern Orientirung halber erlaube ich mir von jet\%t ab tolgende Abkür\%ungen einzuführen: GZ.K.u.= Glockenzelle, Kern unten. - GZ.K.o. = Glockenzelle, Kem obm. - GZ.Kw. = Glockenzellen mit Kern an der vorderen oder hinteren Wand. - GZ.m.K. $=$ Glockenzelle mit mehreren Kernen. - GZ.K.seh.u. $=$ Glockenzelle mit seitlich (schief) unten gelogenem Korn. - GZ.K.sch.o. =.. Glockenzelle nit schief oben (seitlich oben) gelegenem Kern. - P = Lago der Zellen im Protoplasmasinum. - F =:am Fuss des Epithels. $\mathrm{M}=\mathrm{in}$ der Mitte des Epithels innerhalb der Kernzonen.

Sehnitt III. Epithel wie Schnitt II.

1. GZ.K.sch.u., GZ.R.u. und noch sinige undeutliche Zellen

2. GZ.K.u., GZ.K.u., GZ.K.u., einige Kerne, GZ.K.u. $P$.

Schnitt IV wie Schnitt II. GZ.K.sch.u., GZ.K.u., cinzelne Kerne, GZ.K.u, GZ.K.u.

Schnitt V mehr wie Schnitt I. Mehrere undeutliche GZ., dann 2 GZ.K.sch.o., noch mehrere GZ.K.u. (sïmmtl. P), dann eine GZ.K.o. (F).

Sehnitt VI. Einige GZ.K.o. a. GZ.K.w., GZ.K.o. (simmtl. P), damn noch mehrere GZ. Darunter 1 über der ersten Kermeihe (M) GZsch.u., dann 1 GZ.K.u. (P), damn 1 GZ.K.w. (P), 1 GZ.K.o. (P).

Schnitt VII wie Schnitt I. $3 \mathrm{GZ}$. dicht hintereinander. 2 GZ.K.o. $\mathbf{n}$. 1 GZ.K.u $(P)$, noch einige mdeutlich.

Schnitt VIII. 1 GZ.K.o. (P), 1 GZ.K.u., dinn noch einige GZ.K.o.

Schnitt IX. Riechepithel mit respir. Epithel abwechselnd. - 1 Epitholzelle zu einer durch Hämatoxylin intensiv blauen Schleimlangel entartet, daneben 1 GZ.K.u., die in ihrem Aussehen den GZ. ihnolt, aber entschieden etwas bläulich angehauchten Inhalt aufweist. (Schleinige Regener. d. Pigmentglockenzellen). Am Ende des Priiparats 4 GZ. zusammenliegend, 2 GZ.K.u. und 2 GZ.K.o. Dann 1 GZ.K.u. (P), dann 1 GZ.K.o., dann eine (scheinbar) gestielte. Glockenzelle.

Schnitt X. 1 GZ.K.w., dann 1 GZ.K.o. (P), dann 1 GZ.K.o. (F), dann über den ersten 8 Kernreihen 1 GZ.K.o. (M).

Schnitt XI. 2 nebeneinander liegende GZ., 1 GZ.K.o., 1 GZ.K.u., einige GZ.K.u. (P), 1 GZ.2Kerne, 1 GZ.3Kerne, dann 1 GZ.K.w. u. 1 GZ.K.w. (P), 1 GZ.K.u. (F) und einige im Protoplasmasaum.

Schnitt XII-XVIII ergaben ähnliche Bilder. In Schnitt XVIII unter andern vereinzelten GZ. 4 nebeneinander.

Schnitt XIX mater andern 1 (F) GZ.K.o.

Sehnitt XXV. 1 GZ.2Kerne, 1 GZ.K.u. 
Schnitt XXVII. 1 GZ.2K., 1 GZ.2w.K., 1 GZ.2w.K., 1 GZ.2K.o. und u. Schnitt LVII. 1 GZ.2K., 1 GZ.2K.o.

Schnitt LXXIII. 2 GZ. übereinander, die obere $=$ GZ.K.o., clie untere $=$ GZ.K.u., dahinter 1 GZ.K.schr. $\mathbf{u}$.

Schnitt LXXIV. Abermalis 2 GZ. übereinander, die obere K.u., die untere K.o. etc. etc.

Anderes Schleimhautstückchen aus dem obersten, an die lamina cribros. anstossenden Theil des Sept. narium entnommen. Schnitt VIII. 1 Uebergangszelle mit Pigmentlern waudstiindig.

Schnitt XXVII. 1 riesige pigmentirte Glocke.

Schnitt XXVIII. $1 \mathrm{GZ}$, die etwas über das Epithel ragt.

Anderes Sehleim hatstiuck einer mehr dem vorlern Ende der oberen Muschel gegenüberliegenden pigmentirten Stelle des Septum.

Schnitt I. c. 17 GZ. mit versehielener Lage des Kerns (P, einige F). Bowman'sche Drïsen ziemlich reichlich, ohne Degeneration, Olfaetoriustasern deutlich, mit Pigment eingesiumt.

Schnitt X. 1 GZ.Ko.u. (Uehergangszelle?).

Seln itt XXXVIII. Abermals eine.Uebergangstorm wie vorhin.

Sehnitt L. Einige auf dem Epithel liegende GZ.

Die Grössenverhältnisse (Längen- und Breitendurchmesser) der bald runden, bald längss-, bald querovalen Glockenzellen werden durch folgende Zahlen illustrirt: $0,009: 0,009 \mathrm{~mm}$ oder 0,012:0,012 mm (runde); ferner 0,012:0,0075 mm, 0,012:0,0135 $\mathrm{mm}, \quad 0,015: 0,0135 \mathrm{~mm}$. Doch kommen auch $0,03: 0,021 \mathrm{~mm}$ messende, mit $0,006 \mathrm{~mm}$ hohem Kern versehene abnorm grosse Glockenzellen vor. Die Breite des Protoplasmasaums an den mit Riechepithel besetzten Stellen beträgt $0,06-0,081 \mathrm{~mm}$. Die Riechzellenkerne sind in 3 , höchstens 4 Reihen angeordnet, die Stützzellenkerne in 1-2. - Den Grund des Epithels bildet die Kette der Basalzellen und sind letztere gegen die Tumica propr. durch keine deutliche Cuticula getrennt.

In der Tunica propria sind Pigmentzellenzuige verstrent; meist ist das Pigment in rundlichen oder ovalen Zellen angehäuft. Die Bowman'schen Drüsen sind serös und im Bereich ihrer Ausführtungsgänge stellenweise erweitert.

Auch in der Riechschleimhant eines 29jälnrigen, sonst gesund gewesenen Locomotivführers (Albrecht), der an den Folgen einer Scapularfraktur starb, wurden die oben beim Neonatus beschriebenen unpigmentirten Zellen und Kerne im Protoplasmasanm nicht vermisst, desgleichen fanden sich auch pigmentirte Glockenzellen, indess bei Weitem nicht in der grossen Anzahl wie bei 
Vaterlaus ${ }^{1}$ ). Makroskopisch liessen sich abnorme Veränderungen an keiner Stelle der Nasenschleimhaut konstatiren. In der Nisenhöhle befand sich hineingeflossenes Blut und spärliches glasiges Sekret. Im unteren Nasengang lag ein gelbgrünlicher Sekretfetzen. Einige Zupfpräparate frisch 8 Stunden p. m. in 0,73-procentiger Kochsalzlösung untersucht, zeigten Flimmerepithel und zwar schien dieses (von der medialen Fläche der oberen Muschel entnommene) Epithel aus Sinneszellen zu bestehen ${ }^{2}$ ). Trotzdessen ergab die Vergleichung mit (in 7procentigem Sublimat gehärteten) Schnittserien (und zwar von denselben Stellen), dass eine Täuschung hinsichtlich des Epithelcharakters vorlag. Ich fand die mit Flimmern besetzten Stellen wieder, konnte dieselben aber nun bei gut gelungener Kernfürbung nicht mehr als Sinnesepithel, sondern nur als metamorphosirtes respiratorisches Flimmerepithel ansprechen. - Das Geruchsepithel hatte eine zwischen $0,045-0,081 \mathrm{~mm}$ schwankende Höhe. Der Protoplasmasaum, 0,015 mm hoch, ist mit feinsten Härchen versehen, die ganz dentlich zu differenziren sind, aber nicht den Charakter der viel längeren Flimmern tragen. Stützzellenkerne stellenweise deutlich oval, Riechzellenkernzone aus 4 Lagen mit runden Kernen versehener Zellen bestehend. Drüsen zahlreich vorhanden, grösstentheils serösen Charakters, Olfactoriusverzweigungen in der Länge, Quere und schief getroffen. Uebergang von letzten Nervenendigungen in Epithelfussenden nicht zu konstatiren. Pigmentvertheilung wie bei Vaterlaus. Auf längeren Schnitten lässt sich ein grösserer Wechsel im Epithelcharakter konstatiren. So alterniren Inseln deutlichen Geruchsepithels (mit hohem Protoplasmasaum, den beschriebenen unpigmentirten und pigmentirten Glockenzellen, den beiden gut differenzirten Kernzonen) mit Stellen daran stossenden hohen, anscheinend

1) Sollte doch das häufige Einathmen von Menthol, das Vaterlaus zur Linderung seiner Athembeschwerden c. 8 Tag'e lang in verschiedenen Zeiträumen vornahm, zum häufigern Auftreten der Glockenzellen Veranlassung gegeben haben?

2) Ich habe seitdem an drei weiteren Fällen in Zupfpräparaten von derselben Stelle und Partieen unter der lamin. cribrosa, und zwar einmal nach 12, eínmal nach 19, einmal nach 24 Stunden p. m. deutliche Flimmerung konstatirt. Das Epithel ähnelte ausserordentlich dem Riechepithel. Der noch so spät nach dem Tode constatirte Befund der Flimmerung in der Nasenhöhle ist übrigens nichts Auffallendes (cfr. oben M. Schultze's Beobachtungen). 
Beiträge z. feinern norm. Anat. d. menschl. Geruchsorganes. 397

geschichteten Flimmerepithels, dann wiederum einfaches Flimmerepithel mit vollkommen verschleimtem Epithel, während dic Tunica propria noch seröse Drïsen und Olfactorinsfasern mit Pigmentanhäufungen aufweist oder doch neben bereits verschleimten Drüsen sich noch eine Anzahl seröser konstatiren lassen.

Ich könnte die Beispiele von untersuchten Riechschleimhäuten Erwachsener und älterer Kinder noch um einige vermehren, will mich indess zur Vermeidung von Wiederholungen mit der Mittheilung begnügen, dass ich die oben beschriebenen Zellarten in gut entwickeltem Sinnesepithel (es giebt anch verkiimmertes Sinnesepithel, dessen Beschreibung ich mir auf spätere Zeiten aufspare!) nie vermisste.

Die unpigmentirten Zellen sind auf jeder Altersstufe vorhanden, die pigmentirten treten häufiger erst bei älteren Kindern (das jüngste war $6 \frac{1}{2}$ Jahre alt) und Erwachsenen auf. Indess darf man sich nicht mit der Untersuchung einer Stelle der reg. olf. und einzelner Schnitte begnügen, man muss, so umständlich und zeitraubend es auch ist, systematisch die Riechschleimbaut auf Serien durchmustern. Die Vertheilung der pigmentirten Glockenzellen ist nämlich nicht eine regelmässige und wird man ihnen noch am ehesten auf den schon makroskopisch gelblich pigmentirten Stellen des Nasendaches begegnen.

Nachdem diese Zeilen bereits niedergeschrieben waren, kam mir noch ein Fall zur Untersuchung, der besonders schön den Gegensatz zwischen Sinnes- und respiratorischem flimmerndem Epithel zeigte. Ich hatte längere Streifen der reg. olf. (Septum und mediale Fläche der oberen Muschel) entnommen, die gehärtet noch ïber $2 \mathrm{~cm}$ lang waren und konnte mit Leichtigkeit den Wechsel der verschiedenen Epithelarten constatiren. Dazu kam hier noch streckenweise eine vollkommene Vermischung des Epithelcharacters durch massenhafte Auswandertng von Leukocyten - kurzum es liessen sich sämmtliche oben besprochenen Vorgänge an einem Selınitt constatiren. Auch hier wurden die oben besprochenen Zellarten nicht vermisst.

Der besseren Uebersicht halber erlaube ich mir, das Resultat meiner Untersuchungen durch folgendes Resumé zu repräsentiren: 


\section{R es u m é.}

"Das Riechepithel des Mensehen überzieht beim älteren Kinde and beim Erwachsenen nicht in continuo die bisher als Riechgegend beschriebenen Partien der oberen Muschel, der oberen Hälfte der mittleren Muschel, sowie der entsprechenden Partien des Septum (Ausnalimen hicrvon macht nur der gesunde Neonatus), sondern ist auf ganz unregelnaisssig am Nasendach vertheilte Inseln beschränkt ${ }^{1}$ ). Ans diesem Grunde sind Zupfprïparate zur Entscheidung des Epithelcharacters nicht allein milissgebend und künnen zu trügerisehen Schliissen Veranlassung geben. Jerlenfalls muss eine genaue Durehnusterung der gauzen reg. olf. mittelst Selinittserien sich der frischen Untersuchung. und der an Macerationspräparaten ansehliessen.

In selteneren Fillen ist die Gegend des Geruchsepithels durch eine Pigmentirung der Schleimhaut schon makroskopisch angedentet. Im Uebrigen diurf man aus dem Fehlen dieser Verfïrbung nicht anf Abwesenheit von geruchspercipirendeu Elementen schliessen, sowie andererseits eine Pigmentirung an anderen Stellen, die nicht der Gertuchsgegend angehören und die am Septum zienlich weit herabreichen und sich anch am vorderen und unteren Rande der mittleren Mnschel und deren medialer und lateraler Fläche, ja mitunter sogar an der unteren Muschel vorfinden, noch nicht anf Anwesenheit eines Sinnesepithels hinzuweisen braucht. In diesem Falle beschränkt sich die Pigmentirung nur auf verschiedene Stellen der Tunica propria. Anch die Höhe des (im Allgemeinen auf Paraffinschnitten $0,06-0,08 \mathrm{~mm}$ betragenden Geruchsepithels) Epithels, sowie sein grösserer Kernreichthum können ohne die weiterhin zu erwähnenden Kennzeichen nicht zur Diagnose von Sinnesepithel hinreichen. Zu den noch erforderlichen Kriterien gehören:

1) ein Besatz feinster Härchen (Riechhärchen). Derselbe ist niedriger als der Flimmerbesatz des respirirenden Epithels, vulnerabler (wird leicht abgestreift) und kann auf gewisse Strecken einem gestichelten Cuticularsaum äbneln. Diese Aehnlichkeit ist aber bedingt durch Verklebung der Härchen mittelst Sertum, das wahrscheinlich von den Dritsen abge-

1) Wie Schwalbe clas gleichfalls in seinem Lehrbuch angiebt. 
Beiträge z. feinern norm. Anat. d. menschl. Geruchsorganes. 399

sondert, in feinster Schicht die Riechschleimhautoberfläche überzieht. Oft ist der Hürchenbesat\% verdeckt durch Anstritt von Eiweissmassen in Form von Tropfen, Kügelchen, Streifen (postmortal);

2. ein Protoplasmasaum von $0,015-0,018 \mathrm{~mm}$, der ans den peripheren Enden der Stïtz- and Riechzellen besteht (die von $\mathrm{Brunn}$ beschriebene Membr. limit. olf. habe ich nicht differenziren können);

3. das Vorhandensein von unpigmentirten Zellen und freien Kernen, sowie das von pigmentirten, von mir als Glockenzellen benannten Gebilden im Epithel. Erstere sind nur im Protoplasmasaum von anderen Elementen zı differenziren, die zweite Art kormmt an allen Stellen des Epithels vor. Die pigmentirten Glockenzellen finden sich aber nur bei älteren Kindern und Erwachsenen;

4. eventuell: "Differenzirung der Form der Stiitzzellenkerne (oval oder länglich) von der der Riechzellenkerne (runde Form).

Ob diese Differenzen von postmortalen Veränderungen oder Einfluss von Reagentien herrïhren (cf. meine Untersuchungen am Thier!), muss dahin gestellt bleiben. Ich habe auf manchen Schnitten mit nnzweifelhaftem Sinnesepithel nur cinen äusserst geringen Untersehied in der Kernform constatiren können;

כ̃. gehörige Ausbildung der Riechzellenkernzone (3-4 Lagen);

6. Vorhandensein eines Sarumes von Basalzellen, die durch keine Cuticula gegen die Tunica propria abgegrenzt sind;

7. eventuell: Pigmentirung der peripheren Enden der Stiitzzellen (auf Balsampräparaten häufig mangelnd, des starken Lichtbrechung:svermögens des Canadabals. halber);

8. Vorhandensein von unverschleimten mehr minder zahlreichen Bowman'schen Driisen und Olfactoriusfasern in der Tunica propria, sowie Anhäufung von Pigment zwischen den Drüsen und Nerven and um (ja sogar in den Olfactoriusfasern selbst) die Olfactoriusfasern (in die Scheiden!) in Form längerer Zellenzüge oder circumscripterer Häufchen. Von diesem Bilde der menschlichen reg. olf., das ich, weil es dem thierischen noch am nächsten steht, als normal bezeichnen möchte, kommen recht häufig Abweichungen vor. $\mathrm{Ob}$ diese $\mathrm{Ab}$ - 
weichungen noch in das Bereich des Physiologischen gehören, kïnnen nur (mir leider hier in Zürich versagte) Combinationen von klinischen Untersuchungen mittelst Zwaardemaker's Olfactometer und Sectionsergebnissen lehren.

Einen Zusammenhang zwischen Olfactoriusfasern und Sinnesepithelzellen habe ich nicht nachweisen können.

Zum Schluss erlaube ich mir Herrn Professor Klebs für das mir in liberalster Weise zur Verfügung gestellte Untersuchungsmaterial meinen herzlichsten Dank auszusprechen.

\section{Benutzte Literatur.}

1. Babuchin, Das Geruchsorgan (Stricker's Handbuch). Leipzig 1871, Cap. 35.

2. Balogh, Das Jacobson'sehe Organ des Schates. Sitzungsber. der Kaiserl. Akatemie der Wissensch. zu Wien. Bd. 32, 1860.

3. Biermer, Verhandlungen der phys.-med. Ges. zu Würzlourg. Bd. I. $\mathrm{Nr} .14,1850$.

4. Blaue, Untersuchungen üher den Bau der Nasenschleimhaut bei Fischen etc. Arch. f. Anat. u. Physiol. 1884.

5. v. Brunn, Die Membr. limit. olfact. Centralbl. f. med. Wiss. 1874.

6. v. Brunn, Untersuchungen über das Riechepithel. Arch. f. mikr. Anat. XI, 3, 1875.

7. Chatellier, H., Canalicules perforants de la membrane basale de la muqueuse nasale hypertrophée etc. Annales d. malad. de l'oreille etc. Bd. XIII, Nr. 6, p. 233-239.

8. Cis of f, Zur Kenntniss d. reg. olf. Centralbl. f. med. Wissensch. XII, Nr. 44, 1874.

9. Clarke, Zeitsehrift für wissensch. Zoologie. Bd. XI (übersetzt).

10. Colasanti, Unters. über d. Durchschn. d. n. olf. bet Fröschen. Arch. f. Anat. u. Physiol. 1875.

10a. Dircknik-Holmfeld, Experim. Untersuchungen über d. Bau d. regio olf. Nord. med. arch. $X V, 1,83$.

11. Dogiel, Ueber die Drüsen d. reg. olf. Arch. f. mikrosk. Anat. Bd. 26 , S. 50.

11a. Dogiel, Ueber den Bau des Geruchsorganes bei Fischen und Amphibien. Biol. Centralbl. Nr. 14, 1886, S. 428.

12. Ecker, A., Ueber die Geruchsschleimhaut d. Menschen. Zeitschr. f. wissenseh. Zoologie. Vol. VIII, 1856. 
13. Ecker, Icones physiologicae. Taf. VIII.

14. Ecker, Berichte über die Verhandlungen d. Gesch. f. Beförder. d. Naturwissensch. zu Freiburg. Nr. 12. 1855.

15. Eckhardt, Ueber die Endigungsweise der Geruchsnerven. Beiträge zur Anat. u. Physiol. Heft 1, S. 77, 1855.

16. Erichsen, De textura nervi olfactorii. Dorpati 1857. Diss. inaug.

17. Exner, Sitzungsberichte der kaiserl. Akad. d. Wiss. Bd. LXIII. I. Abth. Jan. 1870.

18. Exner, Weitere Studien über d. Struktur der Riechschleimhaut bei Wirbelthieren. Sitzungsber. d. kaiserl. Akad. d. Wissensch. Vol. LXV. IV. Abth. Jan. 1872, S. 27-31.

19. Exner, Sitzungsber. d. K. Akademie. Bd. LXXVI, 3-5.

20. Felisch, Beiträge z. Histologie d. Schleimhaut in d. Lufthöhle d. Pferdekopfes. Diss. 1878.

21. Föttinger, Recherches sur la structure etc. Bull. de l'acad. de Belge 1876.

22. Frey, Lehrbuch der Histologie.

23. Gastaldi, Acad. reale delle Scienze di Torino, Class. mathem. e fis. 2 ser. Tom. XVII, p. 372.

24. Grimm, Ueber das Geruchsorgan der Störe (Göttinger Nachrichten 1872).

25. Grimm, Ueber die Nervenendigungen des Geruchsorgans der Störe. Arbeiten aus der St. Petersh. Gesellsch. d. Naturf. 1873.

26. Henle, Eingeweidlelehre.

27. Hoyer, De tunicae mucosae structure. Diss. inaug. Berolin. 1852 u. in Müller's Archiv 1857.

28. Hoyer, Ueber die mikrosk. Verhältnisse der Nasenschleimhaut verschiedener Thiere $u$. des Menschen. Reichert $u$. Du Bois Archiv 1860 , S. 50.

29. Hoffmann, C. K., Onderzoekingen over den anatom. Bouw van de Membran olfact. en het periph. etc. Amsterdam 1866. Dissert. inaug.

30. Is rael, Practicum der pathol. Histologie. 1889. Hirschwald.

31. Ka ufmann, E., Ueber die Bedeutung der Riech- und Epithelzellen der reg. olf. Mittheil. aus d. embryol. Institut von Dr. Schenk. Wien 1887.

32. Klein, 1) Atlas of Histology u. 2) The Gland of the nasal eavity of the Guinea-pig. Quarterly Journ. of microse. scienc. Vol. XX.

33. Köllike r, Mikrosk. Anatomie. Bd. II, Abth. 2 u. Handbuch der Geburtslehre. 1863.

34. Kölliker, Ueber die Jacobson'schen Organe des Menschen. Gratulationschr. d. Würzh. med. Fakult. für Rinecker. 1877.

35. Kölliker, Zur Entwicklung des Auges u. des Geruchsorganes menschl. Embryonen. Gratulationsschr. f. Zürich. 1883.

36. Krause, Handbuch der menschl. Anatomie. 1876.

37. Krause, Die reg. olf. des Schafes. Diss. inang. Rostock 1881. 
38. Langerhans, Untersuchungen über Petromyzon Planeri. Bericht der naturf. Gesellsch. zu Freiburg (Br.). Bd. VII. 1873.

39. Leydig, Lehrbuch der Histologie des Menschen u. der Thiere. Franlsfurt a. M. $185 \overline{7}$.

40. Löwe, Beitrïge z. Anatomie d. Nase u. Mundhöhle. Berlin 1879.

41. Luschka, Müller's Archiv 1857, S. 3233.

42. Luschka, Das Epithel der Riechschleimhaut d. Menschen. Hed. Centralbl. Nr. 22. 1864.

43. Lustig, Die Degeneration des Epithels der Rjechschleinhatut des Kaninchens ete. Sitzungsber. d. k. k. Akirl. d. Wiss. Wien 1881.

44. Marshall, A. M., Morphology of the vertebrate olfactory Organ. Quart. Journ. of microsc. Science vol. XIX. 1879.

45. Martin (H. Newell), Ueber die Struktur der Riechschleimhant (Journ. of Anat. and Physiol. VIII). 1873.

46. Paulsen, Ed., Ueber die Drüsen der Nasenschleimhant, bes. d. Bowman'sehen Drüsen. Areh. f. mikrosk. Anat. V. Wallkyer ete. Bd. 26. S. 307.

47. Paschtin, Ueber den Batu der Schleimhaut ier reg. olf. des Frosches. Leipziger physiologische Arbeiten. 1873 (Med. Swzertnik 1872).

48. Peregaslawzeft, S ophic, Vorlitufige Mittheilung ïber die Nase der Fische. Diss. inaug. Zïrich 1876.

49. Peregaslawzeff, Sophie, Ueber die Struktur und die Form des Geruchsorganes.

50. Piana, Giov., Ueber das Jacobson'sche Organ. Refer. d. Zeitschrift $f$. Thiermedicin. Bd. VII, S. 325-326.

51. Putelli, Ueber das Verhalten der Zellen der Riechsehleimhat bei Hühnerembryonen früher Stadien. Wien. med. Jalurb. Heft V, S. $183-187.1888$.

52. Ranvier, Techn. Lehrbuch der Histologie. 1877.

53. Rémy, Revue des sciences médicales. Tome XIII, p. 13.

54. Rẻmy, La membrane muqueuse des fosses nasales. Paris 1880.

55. Reichert, Arch. f. Anat. u. Physiol. 1856, Jahresb. S. 41.

56. Retzius, Das Riechepithel der Cyclostomen. Arch. f. Anat. u. Physiol. 1880.

57. Schwalbe, G., Lehrbuch d. Anatomie der Sinnesorgane. 1883, S. 47. ff.

58. Schultze, Max, Monatsber. d. Berl. Akademie. 1856, S. 504.

59. Schultze, Max, Barl der Nasenschleimhaut. Abhandl. d. naturf. Gesellschaft zu Halle. Bd. VII. Halle 1863.

60. Schultze, Max, Das Epithelium der Riechschleimhaut d. Menschen. Med. Centralbi. Nr. 25. 1864.

61. Sa p pey, Gazette méd. de Paris. 1853, p. 543.

62. $\mathrm{Sidk \textrm {y }}$, Recherch. anat. microse. sur la muqueuse olfactive. 1877.

63. S e eberg, R., Disquisitiones microscopicae de textura membranae pitustariae nasi. Dorpat 1856. Dissert. inaug. 
Beiträge z. feinern norm. Anat. d. menschl. Geruchsorganes. 403

64. Stöhr, Ph., Ueber den feineren Ban der respiratorischen Nasenschleimhant. Beitrigge z. mikrosk. Anatomie d. menschl. Körpers. Würzburg. Verhandl. XX, 1.

65. Sussdorf, 1. mikrochem. Reaction auf thierischen Schleim. D. Zeitschr. f. Thiermedicin. Bd. XIV, Heft $5-6$. Leipzig 1889.

66. Toldt, Gewebelehre (Geruchsilpparat). 1877.

67. Todd-Bowman, The Anat. and Physiol. of Man. 1856, vol. II, p. 1-13. (1847 erschien aber bereits die 2. Abtheilung.)

68. Verhandl. d. physic.-med. Gesellsch. zu Wüirburg. Bd. V, S. 17. 1855.

69. Waldey er, Ueber die Riechschleimhaut des Menschen. Archiv f. Psychiatrie und Nervenkrankheiten. Bd. XV, 1, S. 279-280.

70. Welcker-Henle u. Pfeufer's Zeitschr. Bd.XX.

71. Wissozky, N., Ueber dis Eosin als Reagens auf Hiamaglobin etc. Archiv f. mikrosk. Anatomie. Bd. 13, S. 479-496. 1876.

72. Zuckerkandl, E., Beitriige z. Anatomie des menschl. Körpers. Wien. med. Jahrb. VIII. Das adenoide Gewebe d. Nasenschleimhaut. 1886 , S. $219 \mathrm{ff}$.

\section{Erklïrung der Abbildungen auf Tafel XIV.}

Fig. 1a ur. b stellen Paraffinschnitte durch die Riechschleimhaut eines Neugebornen dar (oberste $=4$. Muschel, mediale Fliiche).

Fig. 2a, b stellen einen Celloidinschmitt durch die Riechschleimhaut eines mit gutem Geruchsvermögen ausgestatteten Erwachsenen (45̄j. Indiv.) dar, obere Muschel, mediale Fläche.

Fig. 2c. 35j. Vaterlaus (cf. Text). Paraffinschnitt (mit Mayer's Eiweissglyc. aufgeklebt, in Glycerin-Gelatine eingelegt) reg. olf., obere Muschel, mediale Fläche.

Fig. 3. (Z. Vergleich!) Paraffinschnitt durch die Schleimhaut der unteren Muschel, mediale Fliiche eines Neonatus. Auf diesem Schnitt befinden sich gerade keine secernirenden acinösen Drüsen.

$$
\text { Erklärung der Abkürzungen. }
$$

$\mathrm{Hb}=$ Hürchenbesatz (Riechhärch.).

$\mathrm{Ps}=$ Protoplasmasaum.

Skz $=$ Stiitzzellenkernzone.

Of $=$ Olfactoriusfasern

Rzkz $=$ Riechzellenkernzone.

$\mathrm{Bz}=$ Basalzellen.

$\mathrm{BD}=$ Bowman's Drüsen.

$\mathrm{uZ}=$ unpigmentirte Zellen (cf. den Text).

D (in Fig. 3) = sog. acinöse Drüsen. Fürbung=Delafields Hümatoxylin, $\mathrm{G}=$ Gefüisse.

$\mathrm{P}=$ Pigment.

$\mathrm{PZ}=$ pigmentirte Zellen (im Text $=$ pigmentirte Glockenzellen genannt). schwache Kongolösung. 